\title{
PERAN KEPEMIMPINAN PEREMPUAN DALAM PENGAMBILAN KEPUTUSAN BISNIS
}

\author{
Nur Ika Mauliyah \\ Fakultas Ekonomi dan Bisnis Islam IAIN Jember \\ nurikamauliyab@gmail.com \\ Ella Anastasya Sinambela \\ Universitas Mayjen Sungkono Mojokerto \\ anastasya@gmail.com
}

\begin{abstract}
The chance to be a leader, open for anyone, both men and women. Although, it cannot be denied, culture still considers that women are weak, inconsistent and only concerned with feelings than logic, so they do not deserve to be a leader. As the world develops, the assumption is a little bit of changes, which gives women chance to be a leader. In the $21^{\text {st }}$ century, women's progress in working world was increased dramatically, because the quality of women is sometimes more than men. Getting a quality and high education, giving women have chance to be leader in organizations / companies. Names such as Susi Pudjiastuti, Catherine Hindra Sutjabyo, Grace Tabir, Veronika Linardi, Mary Barra, Gini Rometty, Marillyn Hewson, Sheryl Sandberg, Marissa Mayer are some of the names of women who are able to lead companies and business decision makers. Work decision making is an condition for measuring leaders, women have feminine characteristics which make them able to take business decisions well, by considering rational, realistic, logical, and pragmatic. The mindset that considers leaders only carried out by men has changed step by step. Women can also have character of a leader, such as; give direction, speeches, rhetoric and ideas. Women are not completely weak, they are also able to be a strong foundation in building organizations/ companies.
\end{abstract}

Keywords: Leaders, Women, Decision Makers, Business 


\section{Nur Ika Mauliyah, Ella Anastasya Sinambela}

\section{Abstrak}

Kesempatan menjadi pemimpin, terbuka bagi siapa saja, baik pria maupun wanita. Meski tidak bisa dipungkiri, budaya masih menganggap perempuan lemah, tidak konsisten dan hanya mementingkan perasaan daripada logika, sehingga tidak pantas menjadi pemimpin. Seiring perkembangan dunia, asumsinya adalah sedikit perubahan, yang memberi peluang bagi perempuan untuk menjadi pemimpin. Pada abad ke-21, kemajuan perempuan dalam dunia kerja meningkat drastis, karena kualitas perempuan terkadang lebih dari laki-laki. Mendapatkan pendidikan yang berkualitas dan tinggi, memberikan perempuan kesempatan untuk menjadi pemimpin dalam organisasi / perusahaan. Nama-nama seperti Susi Pudjiastuti, Catherine Hindra Sutjahyo, Grace Tahir, Veronika Linardi, Mary Barra, Gini Rometty, Marillyn Hewson, Sheryl Sandberg, Marissa Mayer adalah beberapa nama perempuan yang mampu memimpin perusahaan dan pengambil keputusan bisnis. Pengambilan keputusan kerja merupakan salah satu syarat untuk mengukur pemimpin, perempuan yang memiliki sifat feminin sehingga mampu mengambil keputusan bisnis dengan baik, dengan mempertimbangkan rasional, realistis, logis, dan pragmatis. Pola pikir yang menganggap pemimpin hanya dilakukan oleh laki-laki berubah sedikit demi sedikit. Wanita juga bisa memiliki karakter seorang pemimpin, seperti; memberi arahan, pidato, retorika dan ide. Perempuan tidak sepenuhnya lemah, mereka juga mampu menjadi fondasi yang kuat dalam membangun organisasi / perusahaan.

\section{Kata Kunci : Pemimpin, Perempuan, Pengambil Keputusan, Bisnis}

\section{Pendahuluan}

Faktor utama dalam keberlangsungan organisasi/ perusahaan adalah kepemimpinan. Seorang pemimpin, memiliki peran yang paling bertanggung jawab terhadap keberhasilan mau- pun kegagalan dalam pekerjaan. Seorang pemimpin, merupakan contoh bagi bawahannya dalam bersikap dan melakukan pekerjaannya. Dalam sejarah, kepemimpinan laki-laki lebih dominan dibandingkan perempuan. Per- 
Vol. 12, No. 1, April 2019

p-ISSN:2086 -0749

e-ISSN:2654-4784

empuan memiliki peran yang juga berkualitas dalam pembangunan kesejahteraan sebuah kelompok, organisasi, atau perusahaan. Perempuan tidak bisa lagi selalu dianggap sebagai peran kedua dalam mengambil keputusan terutama untuk bisnis. Perempuan yang memiliki pendidikan tinggi dan kemampuan manajemen yang kuat, akan memberikan efek kemajuan yang tidak kalah dengan pemimpin laki-laki. Saat ini, peran kesetaraan gender dalam memecahkan dan mengarahkan orang lain bisa dilakukan oleh individu yang memiliki potensi yang paling tinggi di bidangnya, sehingga mampu mencapai tujuan yang telah disepakati oleh organisasi/ perusahaan.

Gaya kepemimpinan itu sendiri berkembang sesuai dengan sifat seseorang yang dibawa sejak lahir, sampai dengan gaya yang demokratis, yang mampu berinteraksi dan mengajak orang lain untuk ikut serta dalam mencapai tujuan organisasi/perusahaan. ${ }^{1}$ Sehingga peran perempuan dalam pengambilan keputusan bukanlah hal yang aneh lagi. Diskriminasi antara perempuan dan laki-laki tidak lagi berguna di kehidupan yang menuntut kualitas daripada kuantitas. Perempuan mampu untuk menyuarakan dan berpartisipasi terhadap pembangunan yang mengarahkan ke kesejahteraan karyawan dan juga organisasi/perusahaan menjadi lebih baik.

Kesempatan untuk menjadi pemimpin dinilai terbuka untuk siapapun, baik itu laki-laki maupun perempuan. Peran perempuan tidak selalu mesti di 'kasur, su-

${ }^{1}$ Bolden, R., Gosling, J., Marturano, A. and Dennison, P. (2003), A Review of Leadership Theory and Competency Frameworks. Centre for Leadership Studies, University of Exeter. UK. p. 561. 


\section{Nur Ika Mauliyah, Ella Anastasya Sinambela}

mur, dan dapur'. Terbukanya kesempatan perempuan sebagai pemimpin, berarti perempuan mampu untuk mengambil keputusan. Disaat budaya masih kental dengan anggapan perempuan adalah makhluk yang lemah, tidak konsisten dan hanya mementingkan perasaan dibandingkan logika sehingga tidak cocok menjadi pemimpin, maka saat dunia semakin berkembang, anggapan tersebut sedikit demi sedikit berubah, yang membuat para perempuan memiliki kesempatan untuk menjadi pemimpin.

\section{Temuan Penelitian dan Pembahasan}

a. Tantangan perempuan dalam kepemimpinan

Perempuan memiliki tantangan yang jauh lebih tinggi dibandingkan laki-laki dalam memimpin organisasi/perusahaan. Banyak sekali tantangan yang harus dihadapi dan diperankan perempuan, jika mau dianggap se- bagai pemimpin yang diakui. Ada beberapa cara yang harus dilakukan oleh perempuan, demi membuat mereka diakui, salah satunya adalah dapat menempatkan diri sebagai motivator dan pengambil keputusan bisnis yang mempunyai prinsip di organisasi/ perusahaan.

Berdasarkan teori yang dikemukakan oleh Timothy A. Judge dkk (2004), bahwa peran kepemimpinan perempuan dalam pengambilan keputusan haruslah memiliki ciri-ciri kreatifitas tersendiri, sehingga mampu merangsang dan memotivasi kreativitas karyawannya, sehingga memberi kualitas antara satu dengan yang lainnya. ${ }^{2}$ Hal tersebut didukung oleh pendapat Nahiya Jaidi Faras, yang menyebutkan bahwa motivasi memberikan ke-

2 Timothy A. Judge, Joyce E. Bono, Remus Ilies and Megan W. Gerhardt (2002), Personality and Leadership: A Qualitative and Quantitative Review, Journal of Applied Psychology 2002 by the America Psychologi Association, Vol. 87, No. 4. p. 765 . 
Vol. 12, No. 1, April 2019

p-ISSN:2086 -0749

e-ISSN:2654-4784

mampuan lebih dalam

perencanaan, pengorganisiran, pengkoordinatoran, sigkronisasi, dan pengambilan keputusan yang mampu dilakukan oleh pemimpin perempuan. $^{3}$

Konsep pemikiran penulis dalam menanggapi tentang kreatifitas seorang pemimpin dalam memberi motivasi, bahwa memang motivasi memberi ciri khas tersendiri terhadap bagaimana seorang pemimpin di mata karyawannya. Disaat organisasi/perusahaan merasa sedang dalam keadaan tidak begitu menguntungkan dan harus menghadapi beberapa masalah, maka peran pemimpin yang mampu memotivasi penting untuk menyemangati para karyawannya, sehingga mampu bersama-sama

\footnotetext{
3 Nahiya Jaidi Faras (1995), Kepemimpinan Wanita Pemimpin dalam Organisasi Wanita, Jurnal Pendidikan Edisi Khusus. Hal. 80.
}

keluar dari masalah yang sedang dihadapi.

Selain motivator, para perempuan memiliki banyak peluang untuk menjadi pemimpin, tetapi agar terlatih dalam hal kepemimpinan, menjadi tantangan terbesar yang harus dihadapi oleh perempuan itu sendiri. Menjadi pemimpin, maka akan menjadi pusat perhatian publik, beda dengan hanya di rumah yang hanya menjadi pusat perhatian keluarga. Memang perempuan, memiliki perbedaan dalam kehidupan seperti hamil dan menyusui anak yang mana kadang kala dianggap 'mengganggu' kinerja, tapi jangan sampai hal tersebut menjadi diskriminasi, sehingga menghancurkan inverstasi kepemimpinan yang ternyata dimiliki oleh para peremuan.

Pengambilan keputusan kerja, menjadi syarat untuk tolak ukur 


\section{Nur Ika Mauliyah, Ella Anastasya Sinambela}

pemimpin, perempuan sendiri memiliki ciri feminim, yang mana ciri tersebut membuat seseorang mampu mengambil keputusan bisnis dengan baik dengan mempertimbangkan rasional, realistis, logis, dan pragmatis. ${ }^{4}$ Pola pikir yang mengganggap pemimpin hanya dilakukan oleh para lakilaki, telah sedikit demi sedikit bergeser. Perempuan ternyata mampu memberi arahan, berorasi, beretorika dan memberi gagasan yang mana kemampuan tersebut adalah kemampuan dari pemimpin. Perempuan terbiasa dengan melihat permasalahan dari berbagai perspektif. Menganalisis kelebihan dan kelemahan dalam sebuah keputusan. Perempuan tidak sepenuhnya lemah, mereka juga mampu menjadi fondasi yang kuat dalam membangun organisasi/perusahaan.

${ }^{4}$ A. Nunuk P. Murniati (2004), Getar Gender (Perempuan Indonesia dalam Perspektif Sosial, Politik, Ekonomi, Hukum, dan HAM, ISBN 979-9375027-4, Magelang, Indonesia Tera. Hal. 57.
Tantangan yang membuat perempuan rentan sebagai pemimpin, karena masih adanya kekerasan yang dilakukan terhadap kaum perempuan. Kekerasan terhadap perempuan, pernikahan dini, upah yang lebih kecil, diskriminasi pekerjaan, menjadi fokus utama agar tidak menghambat peran perempuan menjadi pemimpin yang mampu mengambil keputusan bisnis. Selain itu, budaya yang mengatakan perempuan dibawah laki-laki juga menjadi penghambat adanya kesetaraan gender. Kesetaraan gender harus benar-benar diterapkan dalam dunia kerja, sehingga perempuan memiliki hak-hak yang sama sebagai makhluk sosial atau manusia, dan diberi kesempatan untuk menjadi pemimpin, baik itu dari segi politik, ekonomi, sosial, pendidikan, dan budaya.

Ada dua alasan kenapa perempuan mengalami kesulitan untuk mendapatkan posisi pemimpin, yaitu dikarenakan persepsi 
dan prasangka yang masih menempatkan perempuan di tempat berbeda dan waktu untuk mengurus keluarga benar-benar membebani perempuan. Di Indonesia sendiri, walau sekarang sudah banyak pemimpin perempuannya, tetapi sebagian masih menempatkan pria sebagai monopoli, yang mana kebiasaan tersebut dari zaman dahulu sudah mengakar. Perempuan masih dianggap lemah dan dialihkan perhatiannya dari sikap persamaan gender. ${ }^{5}$

Selain alasan di atas, ada juga beberapa faktor yang menghambat kepemimpinan perempuan, salah satunya adalah faktor agama, dimana tidak menguntungkan perempuan, per-

\footnotetext{
${ }^{5}$ Simatupang, I.F.W.L. (2009), Kepemimpinan Perempuan dalam Birokrasi (Studi Deskriptif pada Kantor Pemerintahan Provinsi Sumatera Utara, Medan). Fakultas Ilmu Sosial dan Ilmu Politik Universitas Sumatera Utara.
}

empuan tidak diberi keluasan untuk mengembangkan dirinya. Pandangan agama masih memberi pandangan distortif terhadap para perempuan. ${ }^{6}$ Pengambilan keputusan bisnis merupakan tindakan pemilihan alternatif yang mana memerlukan delegasi dan otoritas dan memiliki beberapa tahap secara berurutan, yaitu tahap identifikasi, tahap pengembangan, dan tahap seleksi yang akhirnya menentukan keputusan apa yang akan diambil.

Walaupun begitu, perempuan pada masa sekarang mampu untuk bangkit dan memberi warna baru terhadap sebuah organisasi/ perusahaan dalam menentukan keputusan bisni. Perempuan sebagai pemimpin, cenderung mampu memberi sudut pandang pemikiran dan kreasi yang mampu

6 Fauzie Ridjal (1993), Dinamika Gerakan Perempuan di Indonesia, Tiara Wacana Yogya. Yogyakarta. 


\section{Nur Ika Mauliyah, Ella Anastasya Sinambela}

berkembang dan mewujudkan tujuan. Tidak ada yang salah, jika perempuan memiliki hak yang sama untuk menjadi pemimpin. Kepemimpinan sebagai proses yang mampu membuat orang yang diberi amanah mampu bekerja lebih keras dalam menyelesaikan tugas-tugas yang diberikan. Untuk itu, dibutuhkan juga kekuatan untuk mempengaruhi orang lain.

b. Penilaian negatif kepemimpinan perempuan

Gaya kepemimpinan perempuan, yang cenderung menggunakan perasaan daripada nalar, selalu dianggap kelemahan bagi pemimpin wanita. Penilaian emosional ini, diterapkan berdasarkan kehidupan sehari-hari. Penilaian secara emosional dapat menjadi salah satu indikator dalam mengambil sebuah keputusan. Selanjutnya adalah, anggapan mengenai kepemimpinan perempuan hanya sebagai kesetaraan gender dengan tidak adanya kemampuan dari sisi perempuan itu. ${ }^{7}$
Perempuan dianggap tidak memiliki kemampuan dalam segi pendidikan, dan dalam pengambilan keputusan. Jika dilihat dalam kehidupan sehari-hari, perempuan merupakan pemimpin dalam sebuah rumah tangga. Kita mengenal dengan istilah laki-laki adalah pemimpin keluarga, namun sedikit yang mengenal perempuan adalah kepala rumah tangga. Kemampuan perempuan dalam mengatur keluarga selalu dianggap tidak sebanding dengan kemampuan laki-laki dalam menjalankan bisnisnya.

Anggapan perempuan lemah, juga merupakan penilaian negatif dari kepemimpinan perempuan. Di Negara berkembang, ketakutan akan bawahan yang tidak menaruh rasa hormat kepada pemimpin perempuan telah menjadi budaya. Tidak banyak yang mengetahui, bahwa penilaian itu hanya sebatas wacana dan budaya. Sehingga sekali lagi perempuan dianggap lemah tanpa terlebih da- 
Vol. 12, No. 1, April 2019

p-ISSN:2086 -0749

e-ISSN:2654-4784

hulu melihat cara kerja perempuan.

c. Kontribusi perempuan da-

lam pengambil keputusan

bisnis

Kemudian, menurut teori yang diungkapkan oleh Sugeng Haryanto, yang menyebutkan bahwa perempuan mampu memberikan kontribusi yang sangat efektif dalam menambahkan pendapatan rumah tangga, yang mana mereka turun ke dunia kerja karena ingin menambahkan pendapatan keluarga yang dinilai kurang. Awal mula dari hal tersebut, membuat peran perempuan dalam dunia kerja yang mulanya hanya sebagai penambah pendapatan, kini ada yang menjadi pendapatan utama di dalam keluarga, hal tersebut dikarenakan masyarakat merasakan perubahan, dan dikarenakan ada peran perempuan dalam pembangunan. Perempuan banyak yang mampu mandiri secara ekonomi, dan semakin luasnya lapangan pekerjaan yang memerlukan tenaga kerja perempuan. ${ }^{7}$

Menanggapi teori tersebut, konsep pemikiran penulis adalah bahwa dalam mengambil keputusan bisnis, maka akan ada pilihan, yang nanti akan dipilih agar lebih dinamis yang mana dilakukan dulu pertimbangan. Pengambilan keputusan bisnis dilakukan melalui proses yang efesien dan menyesuaikan situasi. Proses yang dilakukan harus dapat menemukan dan mampu menyelesaikan masalah organsasi/perusahaan. Keputusan,

${ }^{7}$ Sugeng Haryanto (2008), Peran Aktif Wanita dalam Peningkatan Pendapatan Rumah Tangga Miskin: Studi Kasus pada Wanita Pemecah Batu di Pucang anak Kecamatan tugu Trenggalek, Jurnal Ekonomi Pembangunan, Vol. 9, No. 2, Desember 2008.

Fiona Gell, Women's Leadership and Participation Case studies on learning for action (London; Routledge, 2005), 65 


\section{Nur Ika Mauliyah, Ella Anastasya Sinambela}

dilakukan demi mempercepat menyelesaikan masalah yang ada, dan demi dapat mengerjakan masalah yang lainnya. Dalam hal kepemimpinan, para pemimpin perempuan mampu melakukan pengontrolan diri, komunikasi yang baik, visi yang baik dan mampu memberi inovasi baru, empati, mengambil keputusan, memiliki kedekatan dengan para bawahan, dan mampu memberikan motivasi.

Memang, saat ini dalam hal kepemimpinan, kemampuan perempuan itu sendiri masih dipertanyakan oleh beberapa pihak, hal tersebut dikarenakan biasanya laki-lakilah yang memiliki peran sebagai pemimpin. Pemikiran tradisional dan belum sepenuhnya mengakui bahwa setiap orang memiliki hak dasar kemanusiaan yang sama, termasuk perempuan, menjadi beberapa hal, kenapa orang-orang masih menganggap sebelah mata terhadap pemimpin perempuan.
Di abad ke-21 ini, kiprah perempuan dalam dunia kerja meningkat drastis, dikarenakan kualitas dari perempuan sendiri kadang kala lebih dari para lakilaki. Mendapatkan pendidikan yang berkualitas dan tinggi, membuat para wanita mempunyai kesempatan untuk memimpin dalam organisasi/perusahaan.

Berikut nama-nama perempuan yang memiliki peran strategis sebagai pemimpin perusahaan besar dan mampu mengambil keputusan bisnis, diantaranya Catherine Hindra Sutjahyo (direktur Zalora Indonesia), Grace Tahir (Direktur Rumah Sakit Mayapada dan co-founder Pilih Dokter), Veronika Linardi (co-founder Qerja), Diajeng Lestari (founder HijUp), Mary Barra (CEO General Motors), Gini Rometty (Ceo, Chairman dan President IBM), Marillyn Hewson (Chairman, CEO, dan President Lockheed Martin), Sheryl Sandberg (COO Facebook), Marissa Mayer (CEO 
dan President Yahoo) dan masih banyak nama-nama perempuan lainnya yang mampu memimpin perusahan dan pengambil keputusan bisnis.

Di Indonesia sendiri, ada satu nama perempuan yang menonjol yaitu Susi Pudjiastuti, beliau selain pemimpin banyak usaha juga merangkap Menteri Kelautan dan Perikanan. Perusahaan yang dipimpin oleh Susi antara lain; Pudjiastuti Marine Product, Eksportir hasil-hasil perikanan dan PT. ASI Pudjiastuti Aviation atau penerbangan Susi Air. Hal ini ditunjukkan oleh Susi, bahwa seorang perempuan memiliki kekuatan untuk pengambil keputusan bisnis atau ekonomi, yang membuat perusahaan Susi tetap eksis dan mampu berkembang, sampai saat ini.

Perempuan, memiliki gaya kepemimpinan yang cenderung melakukan pendekatan dengan ajakan atau demokratik, berbeda dengan laki-laki, yang lebih cenderung menggunakan emosional atau otokratik. Hal ini, selalu dianggap sebagai kelemahan besar, sehingga perempuan dianggap tidak layak menjadi pemimpin. Namun, dalam beberapa aspek, gaya kepemimpinan ini membuat bawahan lebih disiplin dan mengikuti aturan. Laki-laki lebih menekankan status, sedangkan perempuan lebih menekankan hubungan yang erat. Tetapi, kelebihan pemimpin lakilaki tampak, karena mereka mandiri, hirarkis, spesialisasi, dan mampu menggunakan perintah dengan tepat. Perempuan tidak akan mengadopsi cara berpikir pria.

Negara Indonesia saat ini, memiliki masalah yang harus diselesaikan, karena itu dibutuh- 


\section{Nur Ika Mauliyah, Ella Anastasya Sinambela}

kan pemimpin yang ideal, baik dari segi kriteria, popularitas, elektabilitas, kuat, tegas, tulus demi menjaga integritas bangsa. Menurut undang-undang sekalipun, tidak tertulis mengenai perempuan yang tidak boleh menjadi pemimpin. Selain itu belum ada penelitian yang menganggap bahwa perempuan tidak bisa memimpin. Keberhasilan dari tokoh perempuan Indonesia, dapat menjadi acuan mengenai kepemimpinan perempuan. Oleh karena itu, perempuan juga memiliki hak yang sama dalam hal kepemimpinan.

\section{Simpulan}

Perempuan memiliki ciri khasnya sendiri saat menjadi pemimpin, sisi feminim dan maskulin menjadi corak yang menunjukkan gaya kepemimpinan perempuan. Sisi-sisi tersebut, ternyata mampu mengembangkan sifat intuitif, berorientasi, berealisasi, teratur, teguh, peka, cerdas, kreatif, tegas dan berpandangan luas. Pemimpin, harus mampu mengambil keputusan bisnis yang rasional.

Pada era saat ini, banyak perempuan yang telah mendapat pendidikan yang sama dengan laki-laki. Perempuan juga telah dapat mengikuti cara kerja lakilaki, dengan menggunakan indikator kepemimpinan yang baik. Kesempatan perempuan untuk menjadi pemimpin, dapat menjadi tambahan bukti bahwa perempuan juga memiliki kemampuan dalam memimpin.

Peran kepemimpinan perempuan dalam pengambilan keputusan bisnis, dapat terlaksana dengan baik, saat kinerja pemimpin tersebut mampu menjadi penampung pengaduan bawahan, mampu mencari permasalahan, memberikan fasilitas segala kebutuhan, memiliki strategi yang tepat, mampu memberikan motivasi, menciptakan lingkungan kerja yang nyaman, disiplin, dan terbuka. Semua itu, dapat diterapkan 
Vol. 12, No. 1, April 2019

p-ISSN:2086 -0749

e-ISSN:2654-4784

disaat diskriminasi perempuan di lingkungan kerja dihilangkan.

\section{Daftar Pustaka}

A. Nunuk P. Murniati, (2004), Getar Gender (Perempuan Indonesia dalam Perspektif Sosial, Politik, Ekonomi, Hukum, dan $H A M$. Magelang: Indonesia Tera.

Bolden, R., Gosling, J., Marturano, A. and Dennison, P. (2003), A Review of Leadership Theory and Competency Frameworks. Centre for Leadership Studies, University of Exeter. UK.

Fauzie Ridjal (1993), Dinamika Gerakan Perempuan di Indonesia, Yogyakarta: Tiara Wacana.

Fiona Gell, Women's Leadership and Participation Case studies on learning for action, London; Routledge: 2005, 65.

Nahiya Jaidi Faras (1995), Kepemimpinan Wanita Pemimpin dalam Organisasi Wanita, Jurnal Pendidikan Edisi Khusus.

Simatupang, I.F.W.L. (2009), Kepemimpinan Perempuan da- lam Beirokrasi (Studi Deskriptif pada Kantor Pemerintahan Provinsi Sumatera Utara, Medan). Fakultas Ilmu Sosial dan Ilmu Politik Unoersitas Sumatera Utara.

Sugeng Haryanto (2008), Peran Aktif Wanita dalam Peningkatan Pendapatan Rumah Tangga Miskin: Studi Kasus pada Wanita Pemecah Batu di Pucang anak Kecamatan tugu Trenggalek, Jurnal Ekonomi Pembangunan, Vol. 9, No. 2, Desember 2008.

Timothy A. Judge, Joyce E. Bono, Remus Ilies and Megan W. Gerhardt (2002), Personality and Leadership: A Qualitative and Quantitative Review, Journal of Applied Psychology 2002 by the America Psychologi Association, Vol. 87, No. 4. 